\title{
SIFAT-SIFAT MATRIKS YANG TERKAIT DENGAN MATRIKS PARTISI DAN MATRIKS PERMUTASI
}

\author{
AZIZAH AULIA, YANITA, MONIKA RIANTI HELMI \\ Program Studi S1 Matematika, \\ Fakultas Matematika dan Ilmu Pengetahuan Alam, Universitas Andalas, \\ Kampus UNAND Limau Manis Padang, Indonesia. \\ email : eziaulia@gmail.com
}

Diterima 9 Maret 2019 Direvisi 7 April $2019 \quad$ Dipublikasikan 7 Mei 2019

\begin{abstract}
Abstrak. Grup dari representasi grup quaternion dan hasil kali Kronecker memiliki 32 unsur matriks. Tulisan ini akan membahas tentang sifat-sifat yang diperoleh dari pengolahan unsur-unsur matriks suatu grup dari representasi grup quternion dan hasil kali Kronecker. Sifat-sifat ini terkait dengan matriks partisi dan matriks permutasi, serta dengan memperhatikan sifat matriks simetris dan matriks tidak simetris.
\end{abstract}

Kata Kunci: Sifat-sifat Matriks, Matriks Partisi, Matriks Permutasi, Matriks Simetris, Matriks Tidak Simetris

\section{Pendahuluan}

Matriks adalah jajaran empat persegi panjang dari bilangan-bilangan. Bilanganbilangan dalam jajaran tersebut disebut entri dari matriks [1].

Pada tahun 2018, Yanita, dkk [6] mengkaji suatu grup berdasarkan definisi grup quaternion dan diperoleh suatu grup dari representasi grup quaternion dan hasil kali Kronecker tersebut. Grup tersebut adalah $\mathbb{G}=\left\{A_{k}=\left[a_{i j}\right] \mid i, j=1,2,3,4, k=\right.$ $1,2, \cdots, 32\}$ yang memiliki 32 unsur matriks yang dicantumkan pada halaman 3 . Tulisan ini akan membahas sifat-sifat yang muncul dari pengolahan unsur-unsur matriks dari grup tersebut dengan melibatkan matriks partisi dan matriks permutasi serta dengan memperhatikan sifat matriks simetris dan matriks tidak simetris.

\section{Tinjauan Pustaka}

\subsection{Teori Matriks}

Definisi 2.1. [1] Matriks adalah jajaran empat persegi panjang dari bilanganbilangan. Bilangan-bilangan dalam jajaran disebut entri dari matriks.

Definisi 2.2. [2] Suatu matriks yang memiliki baris dan kolom yang sama dinotasikan dengan $A_{n \times n}$, disebut matriks bujursangkar atau matriks kuadrat. 
Definisi 2.3. [1] Sebuah matriks yang seluruh entrinya adalah bilangan nol disebut matriks nol yang disimbolkan dengan 0 .

Definisi 2.4. [1] Matriks identitas adalah matriks bujursangkar dengan bilangan 1 pada diagonal utamanya dan 0 pada entri-entri lainnya.

Definisi 2.5. [4] Jika A adalah matriks kuadrat atau bujursangkar dan berlaku $A=A^{T}$ maka $A$ disebut matriks simetris.

Definisi 2.6. [3] Misalkan $A$ adalah matriks berukuran $n \times n$ (bujursangkar atau matriks kuadrat). A dikatakan matriks segitiga atas jika $a_{i j}=0$ untuk $i>j$. A dikatakan matriks segitiga bawah jika $a_{i j}=0$ untuk $i<j$. A dikatakan matriks diagonal jika $a_{i j}=0$ untuk $i \neq j$, sehingga $A$ dikatakan matriks segitiga atas dan segitiga bawah.

Definisi 2.7. [1] Dua matriks adalah setara jika keduanya memiliki ukuran yang sama dan entri-entri yang bersesuaian adalah sama.

Definisi 2.8. [1] Jika $A$ dan $B$ adalah matriks-matriks dengan ukuran yang sama, maka jumlah $A+B$ adalah matriks yang diperoleh dengan menjumlahkan entri-entri pada $B$ dengan entri-entri yang bersesuaian pada $A$ dan selisih $A-B$ adalah matriks yang diperoleh dengan mengurangkan entri-entri pada $A$ dengan entri-entri yang bersesuaian pada B. Matriks dengan ukuran yang berbeda tidak dapat dijumlahkan atau dikurangkan.

Definisi 2.9. [1] Jika $A$ adalah matriks $m \times n$ dan $B$ adalah matriks $n \times r$ maka hasilkali $A B$ adalah matriks $m \times r$ yang entri-entrinya ditentukan sebagai berikut. Untuk mencari entri pada baris $i$ dan kolom $j$ dari AB, pisahkan baris $i$ dari matriks A dan kolom $j$ dari matriks B. Kalikan entri-entri yang bersesuaian dari baris dan kolom tersebut, dan kemudian jumlahkan hasil yang diperoleh.

\subsection{Matriks Partisi}

Definisi 2.10. [4] Matriks blok atau matriks partisi adalah matriks yang dipartisi atau diblok menjadi beberapa matriks yang ukurannya lebih kecil dengan memasukkan garis horizontal dan vertikal antara baris dan kolom matriks. Matriksmatriks yang ukurannya kecil hasil partisi matriks disebut sub matriks.

\subsection{Matriks Permutasi}

Matriks permutasi terkait dengan matriks identitas yaitu matriks yang diperoleh dengan cara menukarkan baris-baris pada matriks identitas. Hal ini didefinisikan sebagai berikut.

Definisi 2.11. [5] Misalkan $\sigma$ adalah suatu permutasi. Didefinisikan matriks permutasi $P(\sigma)=\left[\delta_{i, \sigma(j)}\right]$, dimana, $\delta_{i, \sigma(j)}=\left\{\begin{array}{ll}1, & \text { jika } i=\sigma(j) \\ 0, & \text { jika } i \neq \sigma(j)\end{array}\right.$, sedemikian sehingga ent $_{i j}(P(\sigma))=\delta_{i, \sigma(j)}$. 
28 Azizah Aulia, dkk

\section{Pembahasan}

Unsur dari grup $\mathbb{G}=\left\{A_{k}=\left[a_{i j}\right] \mid i, j=1,2,3,4, k=1,2, \cdots, 32\right\}$ dengan matriks $A_{k}$ adalah sebagai berikut:

$$
\begin{aligned}
& A_{1}=\left[\begin{array}{llll}
1 & 0 & 0 & 0 \\
0 & 1 & 0 & 0 \\
0 & 0 & 1 & 0 \\
0 & 0 & 0 & 1
\end{array}\right], A_{2}=\left[\begin{array}{cccc}
-1 & 0 & 0 & 0 \\
0 & -1 & 0 & 0 \\
0 & 0 & -1 & 0 \\
0 & 0 & 0 & -1
\end{array}\right], A_{3}=\left[\begin{array}{cccc}
i & 0 & 0 & 0 \\
0 & -i & 0 & 0 \\
0 & 0 & i & 0 \\
0 & 0 & 0 & -i
\end{array}\right], A_{4}=\left[\begin{array}{cccc}
-i & 0 & 0 & 0 \\
0 & i & 0 & 0 \\
0 & 0 & -i & 0 \\
0 & 0 & 0 & i
\end{array}\right], \\
& A_{5}=\left[\begin{array}{cccc}
0 & 1 & 0 & 0 \\
-1 & 0 & 0 & 0 \\
0 & 0 & 0 & 1 \\
0 & 0 & -1 & 0
\end{array}\right], A_{6}=\left[\begin{array}{cccc}
0 & -1 & 0 & 0 \\
1 & 0 & 0 & 0 \\
0 & 0 & 0 & -1 \\
0 & 0 & 1 & 0
\end{array}\right], A_{7}=\left[\begin{array}{cccc}
0 & i & 0 & 0 \\
i & 0 & 0 & 0 \\
0 & 0 & 0 & i \\
0 & 0 & i & 0
\end{array}\right], A_{8}=\left[\begin{array}{cccc}
0 & -i & 0 & 0 \\
-i & 0 & 0 & 0 \\
0 & 0 & 0 & -i \\
0 & 0 & -i & 0
\end{array}\right], \\
& A_{9}=\left[\begin{array}{cccc}
i & 0 & 0 & 0 \\
0 & i & 0 & 0 \\
0 & 0 & -i & 0 \\
0 & 0 & 0 & -i
\end{array}\right], A_{10}=\left[\begin{array}{cccc}
-i & 0 & 0 & 0 \\
0 & -i & 0 & 0 \\
0 & 0 & i & 0 \\
0 & 0 & 0 & i
\end{array}\right], A_{11}=\left[\begin{array}{cccc}
-1 & 0 & 0 & 0 \\
0 & 1 & 0 & 0 \\
0 & 0 & 1 & 0 \\
0 & 0 & 0 & -1
\end{array}\right], A_{12}=\left[\begin{array}{cccc}
1 & 0 & 0 & 0 \\
0 & -1 & 0 & 0 \\
0 & 0 & -1 & 0 \\
0 & 0 & 0 & 1
\end{array}\right], \\
& A_{13}=\left[\begin{array}{cccc}
0 & i & 0 & 0 \\
-i & 0 & 0 & 0 \\
0 & 0 & 0 & -i \\
0 & 0 & i & 0
\end{array}\right], A_{14}=\left[\begin{array}{cccc}
0 & -i & 0 & 0 \\
i & 0 & 0 & 0 \\
0 & 0 & 0 & i \\
0 & 0 & -i & 0
\end{array}\right], A_{15}=\left[\begin{array}{cccc}
0 & -1 & 0 & 0 \\
-1 & 0 & 0 & 0 \\
0 & 0 & 0 & 1 \\
0 & 0 & 1 & 0
\end{array}\right], A_{16}=\left[\begin{array}{cccc}
0 & 1 & 0 & 0 \\
1 & 0 & 0 & 0 \\
0 & 0 & 0 & -1 \\
0 & 0 & -1 & 0
\end{array}\right], \\
& A_{17}=\left[\begin{array}{cccc}
0 & 0 & 1 & 0 \\
0 & 0 & 0 & 1 \\
-1 & 0 & 0 & 0 \\
0 & -1 & 0 & 0
\end{array}\right], A_{18}=\left[\begin{array}{cccc}
0 & 0 & -1 & 0 \\
0 & 0 & 0 & -1 \\
1 & 0 & 0 & 0 \\
0 & 1 & 0 & 0
\end{array}\right], A_{19}=\left[\begin{array}{cccc}
0 & 0 & i & 0 \\
0 & 0 & 0 & -i \\
-i & 0 & 0 & 0 \\
0 & i & 0 & 0
\end{array}\right], A_{20}=\left[\begin{array}{cccc}
0 & 0 & -i & 0 \\
0 & 0 & 0 & i \\
i & 0 & 0 & 0 \\
0 & -i & 0 & 0
\end{array}\right], \\
& A_{21}=\left[\begin{array}{cccc}
0 & 0 & 0 & 1 \\
0 & 0 & -1 & 0 \\
0 & -1 & 0 & 0 \\
1 & 0 & 0 & 0
\end{array}\right], A_{22}=\left[\begin{array}{cccc}
0 & 0 & 0 & -1 \\
0 & 0 & 1 & 0 \\
0 & 1 & 0 & 0 \\
-1 & 0 & 0 & 0
\end{array}\right], A_{23}=\left[\begin{array}{cccc}
0 & 0 & 0 & i \\
0 & 0 & i & 0 \\
0 & -i & 0 & 1 \\
-i & 0 & 0 & 0
\end{array}\right], A_{24}=\left[\begin{array}{cccc}
0 & 0 & 0 & -i \\
0 & 0 & -i & 0 \\
0 & i & 0 & 0 \\
i & 0 & 0 & 0
\end{array}\right], \\
& A_{25}=\left[\begin{array}{llll}
0 & 0 & i & 0 \\
0 & 0 & 0 & i \\
i & 0 & 0 & 0 \\
0 & i & 0 & 0
\end{array}\right], A_{26}=\left[\begin{array}{cccc}
0 & 0 & -i & 0 \\
0 & 0 & 0 & -i \\
-i & 0 & 0 & 0 \\
0 & -i & 0 & 0
\end{array}\right], A_{27}=\left[\begin{array}{cccc}
0 & 0 & -1 & 0 \\
0 & 0 & 0 & 1 \\
-1 & 0 & 0 & 0 \\
0 & 1 & 0 & 0
\end{array}\right], A_{28}=\left[\begin{array}{cccc}
0 & 0 & 1 & 0 \\
0 & 0 & 0 & -1 \\
1 & 0 & 0 & 0 \\
0 & -1 & 0 & 0
\end{array}\right], \\
& A_{29}=\left[\begin{array}{cccc}
0 & 0 & 0 & i \\
0 & 0 & -i & 0 \\
0 & i & 0 & 0 \\
-i & 0 & 0 & 0
\end{array}\right], A_{30}=\left[\begin{array}{cccc}
0 & 0 & 0 & -i \\
0 & 0 & i & 0 \\
0 & -i & 0 & 0 \\
i & 0 & 0 & 0
\end{array}\right], A_{31}=\left[\begin{array}{cccc}
0 & 0 & 0 & -1 \\
0 & 0 & -1 & 0 \\
0 & -1 & 0 & 0 \\
-1 & 0 & 0 & 0
\end{array}\right], A_{32}=\left[\begin{array}{llll}
0 & 0 & 0 & 1 \\
0 & 0 & 1 & 0 \\
0 & 1 & 0 & 0 \\
1 & 0 & 0 & 0
\end{array}\right] \text {. }
\end{aligned}
$$

Matriks-matriks permutasi yang akan digunakan dalam penelitian ini dengan 
matriks $M_{i}$ adalah sebagai berikut:

$$
\begin{aligned}
& M_{1}=\left[\begin{array}{cc}
P A & Q B \\
C & D
\end{array}\right], M_{2}=\left[\begin{array}{cc}
P A & B \\
Q C & D
\end{array}\right], M_{3}=\left[\begin{array}{cc}
P A & B \\
C & Q D
\end{array}\right], M_{4}=\left[\begin{array}{cc}
Q A & P B \\
C & D
\end{array}\right],
\end{aligned}
$$

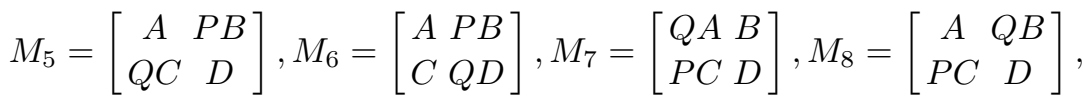

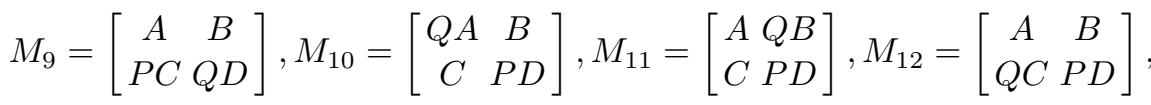

dengan $A, B, C, D$ merupakan submatriks berukuran $2 \times 2$ hasil partisi dari $A_{k}$, matriks $P=\left[\begin{array}{ll}1 & 0 \\ 0 & 1\end{array}\right]$ dan matriks $Q=\left[\begin{array}{ll}0 & 1 \\ 1 & 0\end{array}\right]$.

Teorema 3.1. Misalkan $A_{k} \in \mathbb{G}$, maka $A_{k} A_{k}^{T}=A_{k}^{T} A_{k}$ untuk setiap $A_{k} \in \mathbb{G}$.

Bukti. Pembuktian teorema di atas akan dibagi dalam beberapa kasus, yaitu sebagai berikut.

Kasus 1. Akan dibuktikan bahwa Teorema 3.1 berlaku untuk matriks $A_{k} \in \mathbb{G}$ yang simetris.

Ambil sebarang matriks $A_{k} \in \mathbb{G}$ yang simetris.

Berdasarkan Definisi 2.5, jika $A_{k}$ matriks simetris, maka $A_{k}=A_{k}{ }^{T}$.

Perhatikan bahwa:

$$
\begin{aligned}
A_{k} \cdot A_{k}^{T} & =A_{k} \cdot A_{k} \\
& =A_{k}^{T} \cdot A_{k} .
\end{aligned}
$$

Jadi terbukti bahwa $A_{k} A_{k}^{T}=A_{k}^{T} A_{k}$ untuk matriks $A_{k} \in \mathbb{G}$ yang simetris.

Kasus 2. Akan dibuktikan bahwa Teorema 3.1 berlaku untuk matriks $A_{k}$ yang tidak simetris.

Ambil sebarang matriks $A_{k} \in \mathbb{G}$ yang tidak simetris.

Karena $A_{k}=\left[a_{i j}\right]$ matriks tidak simetris, maka $A_{k}^{T}=\left[-a_{i j}\right]$, untuk $i=1,2,3,4$ dan $j=1,2,3,4$

Perhatikan bahwa:

$$
\begin{aligned}
A_{k} \cdot A_{k}^{T} & =\left[a_{i j}\right] \cdot\left[-a_{i j}\right] \\
& =\left[\sum_{k=1}^{n} a_{i k} \cdot-a_{k j}\right] \\
& =\left[\sum_{k=1}^{n}-\left(a_{i k}\right) \cdot a_{k j}\right] \\
& =\left[-a_{i j}\right] \cdot\left[a_{i j}\right] \\
& =A_{k}^{T} \cdot A_{k} .
\end{aligned}
$$

Jadi terbukti bahwa $A_{k} A_{k}^{T}=A_{k}^{T} A_{k}$ untuk matriks $A_{k} \in \mathbb{G}$ yang tidak simetris. Berdasarkan kasus 1 dan kasus 2 , terbukti untuk setiap $A_{k} \in \mathbb{G}$, maka $A_{k} A_{k}{ }^{T}=$ $A_{k}^{T} A_{k}$. 
30 Azizah Aulia, dkk

Teorema 3.2. Misalkan $X, Y \in \mathbb{G}$, maka $X Y^{T}=X^{T} Y$ untuk setiap $X, Y \in \mathbb{G}$, dengan syarat $X$ dan $Y$ keduanya matriks simetris atau $X$ dan $Y$ keduanya matriks tidak simetris.

Bukti. Pembuktian Teorema 3.2 dibagi menjadi beberapa kasus berikut.

Kasus 1. Akan dibuktikan Teorema 3.2 berlaku untuk matriks $X$ simetri dan matriks $Y$ simetris.

Berdasarkan Definisi 2.5, jika $X$ matriks simetris, maka $X=X^{T}$.

Berdasarkan Definisi 2.5, jika $Y$ matriks simetris, maka $Y=Y^{T}$.

Perhatikan bahwa :

$$
\begin{aligned}
X \cdot Y^{T} & =X^{T} \cdot Y^{T} \\
& =X^{T} \cdot Y .
\end{aligned}
$$

Jadi terbukti bahwa $X Y^{T}=X^{T} Y$ untuk matriks $X$ dan $Y$ keduanya matriks simetris.

Kasus 2. Akan dibuktikan Teorema 3.2 berlaku untuk matriks $X$ tidak simetris dan $Y$ tidak simetris.

Ambil sebarang matriks $X \in \mathbb{G}$ yang tidak simetris, dan matriks $Y \in \mathbb{G}$ yang tidak simetris.

Jika matriks $X$ tidak simetris, maka $X^{T}=-X=-\left[x_{i j}\right]$, untuk $i=1,2,3,4$ dan $j=1,2,3,4$

Jika matriks $Y$ tidak simetris, maka $Y^{T}=-Y=-\left[y_{i j}\right]$, untuk $i=1,2,3,4$ dan $j=1,2,3,4$

Perhatikan bahwa :

$$
\begin{aligned}
X \cdot Y^{T} & =\left[x_{i j}\right] \cdot-\left[y_{i j}\right] \\
& =\left[\sum_{k=1}^{n} x_{i k} \cdot-y_{k j}\right] \\
& =\left[-\sum_{k=1}^{n} x_{i k} \cdot y_{k j}\right] \\
& =-\left[\sum_{k=1}^{n} x_{i k} \cdot y_{k j}\right] \\
X^{T} \cdot Y & =-\left[x_{i j}\right] \cdot\left[y_{i j}\right] \\
& =\left[\sum_{k=1}^{n}-x_{i k} \cdot y_{k j}\right] \\
& =\left[-\sum_{k=1}^{n} x_{i k} \cdot y_{k j}\right] \\
& =-\left[\sum_{k=1}^{n} x_{i k} \cdot y_{k j}\right]
\end{aligned}
$$


Berdasarkan persamaan-persamaan di atas, karena persamaan (3.1) sama dengan persamaan (3.2), maka terbukti bahwa $X Y^{T}=X^{T} Y$ untuk matriks $X$ dan $Y$ keduanya matriks tidak simetris.

Berdasarkan kasus 1 dan kasus 2, maka terbukti $X Y^{T}=X^{T} Y$ untuk setiap $X, Y \in \mathbb{G}$, dengan syarat $X$ dan $Y$ keduanya matriks simetris atau $X$ dan $Y$ keduanya matriks tidak simetris.

Teorema 3.3. Misalkan

$$
X=\left[\begin{array}{cccc}
A_{11} & 0 & \cdots & 0 \\
A_{21} & A_{22} & \cdots & 0 \\
\vdots & \vdots & \ddots & \vdots \\
A_{n 1} & A_{n 2} & \cdots & A_{n n}
\end{array}\right] \text { dan } Y=\left[\begin{array}{cccc}
A_{11} & A_{21} & \cdots & A_{n 1} \\
0 & A_{22} & \cdots & A_{n 2} \\
\vdots & \vdots & \ddots & \vdots \\
0 & 0 & \cdots & A_{n n}
\end{array}\right]
$$

dimana $A_{i j}$ dengan $i=1,2, \cdots, n$ dan $j=1,2, \cdots, n$ adalah matriks-matriks di $\mathbb{G}$, maka $X^{T} X=Y Y^{T}$ dengan syarat $A_{i j}$ adalah matriks simetris atau $A_{i j}$ adalah matriks tidak simetris.

Bukti. Ambil sebarang matriks $A_{i j} \in \mathbb{G}$.

$$
\begin{aligned}
& \text { Matriks } X=\left[\begin{array}{cccc}
A_{11} & 0 & \cdots & 0 \\
A_{21} & A_{22} & \cdots & 0 \\
\vdots & \vdots & \ddots & \vdots \\
A_{n 1} & A_{n 2} & \cdots & A_{n n}
\end{array}\right] \text {, maka } X^{T}=\left[\begin{array}{cccc}
A_{11}{ }^{T} & A_{21}{ }^{T} & \cdots & A_{n 1}{ }^{T} \\
0 & A_{22}{ }^{T} & \cdots & A_{n 2}{ }^{T} \\
\vdots & \vdots & \ddots & \vdots \\
0 & 0 & \cdots & A_{n n}{ }^{T}
\end{array}\right] \text {, } \\
& X^{T} X=\left[\begin{array}{cccc}
A_{11}{ }^{T} & A_{21}{ }^{T} & \cdots & A_{n 1}{ }^{T} \\
0 & A_{22}{ }^{T} & \cdots & A_{n 2}{ }^{T} \\
\vdots & \vdots & \ddots & \vdots \\
0 & 0 & \cdots & A_{n n}{ }^{T}
\end{array}\right]\left[\begin{array}{cccc}
A_{11} & 0 & \cdots & 0 \\
A_{21} & A_{22} & \cdots & 0 \\
\vdots & \vdots & \ddots & \vdots \\
A_{n 1} & A_{n 2} & \cdots & A_{n n}
\end{array}\right] \\
& =\left[\begin{array}{cccc}
A_{11}{ }^{T} A_{11}+A_{21}{ }^{T} A_{21}+\ldots+A_{n 1}{ }^{T} A_{n 1} & A_{21}{ }^{T} A_{22}+\ldots+A_{n 1}{ }^{T} A_{n 2} & \cdots & A_{n 1}{ }^{T} A_{n n} \\
A_{22}{ }^{T} A_{21}+\ldots+A_{n 2}{ }^{T} A_{n 1} & A_{22}{ }^{T} A_{22}+\ldots+A_{n 2}{ }^{T} A_{n 2} & \cdots & A_{n 2}{ }^{T} A_{n n} \\
\vdots & \vdots & \ddots & \vdots \\
A_{n n}{ }^{T} A_{n 1} & A_{n n}{ }^{T} A_{n 2} & \cdots & A_{n n}{ }^{T} A_{n n}
\end{array}\right] .
\end{aligned}
$$

Matriks $Y=\left[\begin{array}{cccc}A_{11} & A_{21} & \cdots & A_{n 1} \\ 0 & A_{22} & \cdots & A_{n 2} \\ \vdots & \vdots & \ddots & \vdots \\ 0 & 0 & \cdots & A_{n n}\end{array}\right]$, maka $Y^{T}=\left[\begin{array}{cccc}A_{11}{ }^{T} & 0 & \cdots & 0 \\ A_{21}{ }^{T} & A_{22}{ }^{T} & \cdots & 0 \\ \vdots & \vdots & \ddots & \vdots \\ A_{n 1}{ }^{T} & A_{n 2}{ }^{T} & \cdots & A_{n n}{ }^{T}\end{array}\right]$, 


$$
\begin{aligned}
Y Y^{T}= & {\left[\begin{array}{cccc}
A_{11} & A_{21} & \cdots & A_{n 1} \\
0 & A_{22} & \cdots & A_{n 2} \\
\vdots & \vdots & \ddots & \vdots \\
0 & 0 & \cdots & A_{n n}
\end{array}\right]\left[\begin{array}{cccc}
A_{11}{ }^{T} & 0 & \cdots & 0 \\
A_{21}{ }^{T} & A_{22}{ }^{T} & \cdots & 0 \\
\vdots & \vdots & \ddots & \vdots \\
A_{n 1}{ }^{T} & A_{n 2}{ }^{T} & \cdots & A_{n n}{ }^{T}
\end{array}\right] } \\
= & {\left[\begin{array}{ccccc}
A_{11} A_{11}{ }^{T}+A_{21} A_{21}{ }^{T}+\ldots+A_{n 1} A_{n 1}{ }^{T} & A_{21} A_{22}{ }^{T}+\ldots+A_{n 1} A_{n 2}{ }^{T} & \cdots & A_{n 1} A_{n n}{ }^{T} \\
A_{22} A_{21}{ }^{T}+\ldots+A_{n 2} A_{n 1}{ }^{T} & A_{22} A_{22}{ }^{T}+\ldots+A_{n 2} A_{n 2}{ }^{T} & \cdots & A_{n 2} A_{n n}{ }^{T} \\
\vdots & \vdots & \ddots & \vdots \\
& A_{n n} T A_{n 2}{ }^{T} & \cdots & A_{n n} A_{n n}{ }^{T}
\end{array}\right] . }
\end{aligned}
$$

Perhatikan bahwa berdasarkan Teorema 3.1 dan Teorema 3.2

$$
\begin{aligned}
& X^{T} X=\left[\begin{array}{cccc}
A_{11}{ }^{T} A_{11}+A_{21}{ }^{T} A_{21}+\ldots+A_{n 1}{ }^{T} A_{n 1} & A_{21}{ }^{T} A_{22}+\ldots+A_{n 1}{ }^{T} A_{n 2} & \cdots & A_{n 1}{ }^{T} A_{n n} \\
A_{22}{ }^{T} A_{21}+\ldots+A_{n 2}{ }^{T} A_{n 1} & A_{22}{ }^{T} A_{22}+\ldots+A_{n 2}{ }^{T} A_{n 2} & \cdots & A_{n 2}{ }^{T} A_{n n} \\
\vdots & \vdots & \ddots & \vdots \\
A_{n n}{ }^{T} A_{n 1} & A_{n n}{ }^{T} A_{n 2} & \cdots & A_{n n}{ }^{T} A_{n n}
\end{array}\right] \\
& =\left[\begin{array}{cccc}
A_{11} A_{11}{ }^{T}+A_{21} A_{21}{ }^{T}+\ldots+A_{n 1} A_{n 1}{ }^{T} & A_{21} A_{22}{ }^{T}+\ldots+A_{n 1} A_{n 2}{ }^{T} & \cdots & A_{n 1} A_{n n}{ }^{T} \\
A_{22} A_{21}{ }^{T}+\ldots+A_{n 2} A_{n 1}{ }^{T} & A_{22} A_{22}{ }^{T}+\ldots+A_{n 2} A_{n 2}{ }^{T} & \cdots & A_{n 2} A_{n n}{ }^{T} \\
\vdots & \vdots & \ddots & \vdots \\
A_{n n} A_{n 1}{ }^{T} & A_{n n} T A_{n 2}{ }^{T} & \cdots & A_{n n} A_{n n}{ }^{T}
\end{array}\right] \\
& =Y Y^{T} \text {. }
\end{aligned}
$$

Berdasarkan pembuktian di atas, maka terbukti bahwa apabila

$$
X=\left[\begin{array}{cccc}
A_{11} & 0 & \cdots & 0 \\
A_{21} & A_{22} & \cdots & 0 \\
\vdots & \vdots & \ddots & \vdots \\
A_{n 1} & A_{n 2} & \cdots & A_{n n}
\end{array}\right] \text { dan } Y=\left[\begin{array}{cccc}
A_{11} & A_{21} & \cdots & A_{n 1} \\
0 & A_{22} & \cdots & A_{n 2} \\
\vdots & \vdots & \ddots & \vdots \\
0 & 0 & \cdots & A_{n n}
\end{array}\right]
$$

dimana $A_{i j}$ dengan $i=1,2, \cdots, n$ dan $j=1,2, \cdots, n$ adalah matriks-matriks di $\mathbb{G}$, maka $X^{T} X=Y Y^{T}$ dengan syarat $A_{i j}$ adalah matriks simetris atau $A_{i j}$ adalah matriks tidak simetris.

\section{Kesimpulan}

Sifat-sifat yang muncul pada pengolahan unsur-unsur matriks suatu grup $\mathbb{G}=$ $\left\{A_{k}=\left[a_{i j}\right] \mid i, j=1,2,3,4, k=1,2, \cdots, 32\right\}$ dengan melibatkan matriks partisi dan matriks permutasi serta dengan memperhatikan sifat matriks simetris dan matriks tidak simetris adalah sebagai berikut :

(1) Untuk setiap matriks $A_{k} \in \mathbb{G}$, yaitu $A_{k}=\left[\begin{array}{ll}A & B \\ C & D\end{array}\right], A, B, C, D$ merupakan submatriks berukuran $2 \times 2$ dari $A_{k}$. Dan untuk setiap matriks permutasi $M_{i}$, $i=1,2, \cdots, 12$ dengan matriks $P=\left[\begin{array}{ll}1 & 0 \\ 0 & 1\end{array}\right]$ dan matriks $Q=\left[\begin{array}{ll}0 & 1 \\ 1 & 0\end{array}\right]$, maka jika 
matriks $Q=\left[\begin{array}{ll}0 & 1 \\ 1 & 0\end{array}\right]$ bertemu dengan submatriks dari $A_{k}=[0]$ maka matriks $M_{i}=A_{k}$.

(2) Matriks permutasi $M_{4}=M_{7}=M_{10}, M_{1}=M_{8}=M_{11}, M_{2}=M_{5}=M_{12}$, dan $M_{3}=M_{6}=M_{9}$.

(3) Untuk setiap $A_{k} \in \mathbb{G}$, berlaku $A_{k} A_{k}{ }^{T}=A_{k}{ }^{T} A_{k}$.

(4) Untuk setiap $X, Y \in \mathbb{G}$, berlaku $X Y^{T}=X^{T} Y$ dengan syarat $X$ dan $Y$ keduanya matriks simetris atau $X$ dan $Y$ keduanya matriks tidak simetris.

(5) Jika dibentuk matriks segitiga bawah $X$ dengan entri-entrinya adalah matriksmatriks dari $\mathbb{G}$, dan dibentuk matriks segitiga atas $Y$ dengan entri-entrinya adalah matriks-matriks dari $\mathbb{G}$ dengan syarat $A_{i j}=A_{j i}$ untuk $i=1,2, \cdots, n$ dan $j=1,2, \cdots, n$ maka berlaku $X^{T} X=Y Y^{T}$ dengan syarat semua matriks yang merupakan entri dari $X$ dan $Y$ adalah matriks simetris atau semua matriks yang merupakan entri dari $A$ dan $B$ adalah matriks tidak simetris.

\section{Ucapan Terima kasih}

Penulis mengucapkan terima kasih kepada Ibu Nova Noliza Bakar, M.Si, Bapak Prof. I Made Arnawa, dan Bapak Dr. Effendi yang telah memberikan masukan dan saran sehingga tulisan ini dapat diselesaikan dengan baik.

\section{Daftar Pustaka}

[1] Anton, H. dan Rorres, C. 2004. Aljabar Linear Elementer; edisi ke-8, terjemahan. Erlangga, Jakarta.

[2] Lipschutz, S. and Lipson, M.L. 2001. Schaum's Outlines Aljabar Linier, edisi ke-3. Erlangga, Jakarta.

[3] Jacob, B. 1990. Linear Algebra, W.H.Freeman and Company, New York.

[4] Supranto, J. 1993. Pengantar Matriks. Fakultas Ekonomi Universitas Indonesia, Jakarta.

[5] Piziak, R and Odell, P.L. 2007. Matrix Theory From Generalized Inverses to Jordan Form, Taylor and Francis Group, Canada.

[6] Yanita; Helmi, M.R dan Zakiya, A. 2018. Solvability Group From Kronecker Product on the Representation of Quaternion Group. Akan terbit di Asian Journal of Scientific Science. http://docsdrive.com/pdfs/ansinet/ajsr/0000/9212392123.pdf. 